\title{
Dilemas da (re)inserção pelo trabalho na saúde mental
}

\author{
The Dilemmas Of(Re)Integration Through Occupational Mental Healthcare
}

\section{Felizardo Tchiengo Bartolomeu COSTA*}

http://orcid.org/o0oo-0003-2546-340X

José Sterza JUSTO**

http://orcid.org/0000-0002-5472-9900

Resumo: O objetivo deste artigo é problematizar, por meio de um estudo teórico, a reinserção social plena dos usuários de saúde mental pelo trabalho e como nela se implica a questão do sofrimento produzido pela lógica capitalística. Para tal, foram tomados autores e teorias que permitiram levantar e discutir articulações históricas entre trabalho e loucura, bem como concepções subjacentes a práticas produzidas no campo da Reforma Psiquiátrica, tais como: oficinas de trabalho e geração de renda. Como principal conclusão é assinalada a grande dificuldade em se conciliar, no estágio atual do capitalismo, a reinserção no trabalho com a produção de saúde mental ou com estratégias de cuidado a pessoas em sofrimento psíquico.

Palavras-chave: Trabalho. Saúde mental. Oficinas terapêuticas.

Abstract: The aim of this article is to discuss, through a theoretical study, the full social reintegration of mental health service users through occupational therapy and its implications for the issue of suffering produced by capitalism. To do this, authors and theories have been selected that allow us to raise and make historical links between work and mental disorders, as well as the concepts underlying practices in the field of Psychiatric Reform, such as occupational therapy workshops for employment and income generation. The conclusion highlights the great difficulty in reconciling, in the current stage of capitalism, reintegration into work with the production of mental health or with care strategies for those suffering psychologically.

Keywords: Work. Mental health. Therapeutic workshops.

Submetido em: 31/3/2020. Aceito em: 3/6/2020.

\footnotetext{
* Psicólogo. Doutor em Psicologia. Professor Auxiliar da Escola Superior Pedagógica do Bengo. Rua direita da, Açucareira, Angola. (ESPB, Bengo, Angola). E-mail: felicosta_4@hotmail.com.

** Psicólogo. Doutor em Psicologia. Professor Livre-Docente do Programa de Pós-Graduação em Psicologia da Faculdade de Ciências e Letras da Universidade Estadual Paulista (UNESP, Assis, Brasil). Av. Dom Antonio, 2100, Parque Universitário, Assis (SP), CEP 19806-900. E-mail: sterzajusto@yahoo.com.br.
} copiar e redistribuir o material em qualquer suporte ou formato, bem como adaptar, transformar e criar a partir deste material para qualquer fim, mesmo que comercial. O licenciante não pode revogar estes direitos desde que você respeite os termos da licença. 


\section{Introdução}

$\mathrm{O}$ objetivo deste artigo é problematizar a reinserção social plena ${ }^{1}$, por meio do trabalho, dos usuários da saúde mental e como nela se implica a questão do sofrimento produzido pela lógica capitalística. Para tal, será feita uma breve retomada histórica das apropriações do trabalho pela psiquiatria tradicional e mais recentemente, pela saúde mental e, em seguida, serão focalizadas as oficinas de trabalho e geração de renda como forma preferencial do uso do trabalho e da atividade nos modelos emergentes de atenção em saúde mental. Por fim, será discutida e problematizada a ética ou a-ética do trabalho no capitalismo, de forma a se situar num modo de produção colocado a serviço do capital e não da melhoria das condições dos usuários da saúde mental, a partir da hipótese de que é difícil produzir saúde ou potencializar processos de subjetivação/singularização na lógica capitalística, ou seja, recorrer a um trabalho alienante, ele próprio se constituindo como importante fonte produtora de sofrimento.

Nesse paradoxo que se forma entre saúde e trabalho, no modo de produção capitalista, é necessário examinar, criticamente, as práticas psicoterapêuticas baseadas em oficinas de trabalho e geração de renda para que não venham a assumir uma função equivalente a dos medicamentos, silenciando conflitos e tamponando sintomas.

\section{Breve histórico da apropriação do trabalho por instituições e serviços de saúde mental}

As tentativas de se usar o trabalho para lidar com a loucura estão longe de serem ideias inovadoras. Contudo, as diferenças seriam, antes, dadas pelo sentido que o trabalho assume nas diferentes abordagens orientadoras das práticas nos serviços de atenção em saúde mental. A este respeito, por exemplo, Valladares, Lappann-Botti, Mello, Kantorski e Scatena (2003), referem que o trabalho, no âmbito da saúde mental, esteve, primeiramente, dentro da visão de tratamento moral. Eles citam Rocha (1912, p. 6) que defendia o seguinte:

Não se deve [...], olhar somente o valor da produção, que é grande, mas também o lado moral da questão. O insano que trabalha e vê o resultado de seu suor, sente-se mais digno; sai da condição ínfima de criatura inútil e elevase a seus próprios olhos; adapta-se ao modus vivendi que lhe suaviza, grandemente, a desgraça (VALLADARES; LAPPANN-BOTTI; MELLO; KANTORSKI; SCATENA, 2003 apud ROCHA, 1912, p. 6).

Podemos dizer também, que historicamente, o trabalho foi sendo utilizado como meio, pelo qual se acreditava na restituição da moral dos sujeitos em sofrimento psíquico. Neste sentido, estar mentalmente doente representaria a ruptura com a vida produtiva, o fim da capacidade de criar, encaminhando o sujeito para o ócio. As compreensões de loucura e trabalho modificaram-se ao longo da História, tanto nas concepções a ela

\footnotetext{
${ }^{1}$ Optamos por utilizar a expressão reinserção social plena, pois achamos que apenas reinserção social não seria suficiente para dar a dimensão do pretendemos problematizar, que os usuários são parte da sociedade, porém, dentro da lógica da inclusão pela exclusão e não por meio de uma inclusão plena, sem as restrições que lhes são imputadas pela sua condição.
} 
atribuída como nas práticas produzidas a partir dessas concepções (FOUCAULT, 1978; ANDRADE; BURALI; VIDA; FRANSOZIO; SANTOS, 2013).

Foucault (1978, p. 7) na história da loucura aparece percorrendo a genealogia das práticas de internação, práticas estas consideradas precursoras das prisões e manicômios modernos, ele menciona o surgimento, na Inglaterra do século XVII, amparado em lei, de casas de correção para o recolhimento de pobres, vagabundos e demais enjeitados, impondo-lhe o trabalho obrigatório, como forma de punição. Tratava-se de um trabalho que deveria ser rentável, produtivo e não apenas uma mera ocupação.

Prossegue o autor esclarecendo que "O século XIX aceitará e mesmo exigirá que se atribuam, exclusivamente, aos loucos esses lugares nos quais cento e cinquenta anos antes se pretendeu alojar os miseráveis, vagabundos e desempregados" (FOUCAULT, 1978, p. 83) Os manicômios prosseguiram a prática da correção moral da ociosidade, impingida, também, aos loucos desde o surgimento das internações quando eram confinados, indistintamente, com seus antigos parceiros que representavam a vagabundagem e a ociosidade.

Uma questão importante a ser considerada na valorização do trabalho, desde a época clássica e que será prolongada e acentuada na modernidade, é que se trata não, propriamente, de uma tentativa de inserir ou submeter todos à obrigatoriedade da produção mas, com ela e, principalmente, de utilizar o trabalho como correção moral. Conforme salienta Foucault (1978), "Com efeito, a relação entre a prática do internamento e as exigências do trabalho não é definida inteiramente - longe disso pelas condições da economia. Sustenta-a e anima-a uma percepção moral" (FOUCAULT, 1978, p. 84). Como a pobreza e desemprego não eram atribuídos ao funcionamento da economia, com se faz até hoje, era imputada aos indivíduos a responsabilidade pelos seus infortúnios e mazelas. Pobres e desempregados, à semelhança do que ocorre na atualidade, eram considerados pessoas degradadas moralmente, vagabundos inveterados que se compraziam com a ociosidade.

Nessa mesma linha de livrar as reponsabilidades da economia pela produção da miséria, atribui-se ao próprio sujeito, ainda hoje, a responsabilidade pela sua condição de pobreza ou de desempregado, imputando-lhe uma pressuposta inaptidão, falta de qualificação profissional ou mesmo uma falta de apetite pelo trabalho ou pelo empreendedorismo. Mesmo com novas roupagens, persiste a condenação moral daqueles descartados do mundo do trabalho.

Valladares, et al. (2003) se reportam a Rocha (1912) o qual asseverava que a ociosidade é o que há de mais subversivo, tanto para o louco quanto para o normal. $\mathrm{O}$ não fazer nada era visto como indesejável e imoral e, por isso, nada mais lógico do que combatêlo com aquele que podia ser entendido como o único instrumento capaz de realizar tal apanágio: o trabalho. É assim que, segundo Guerra (2004), o lazer indefinido de um labor inútil delineia o território sobre o qual se desenvolverá, futuramente, a psiquiatria e, em seu seio, o uso da atividade e do trabalho, enquanto recurso terapêutico. Porém, no caso do louco, ele seria assistido e não remunerado. 
Simetricamente ao reconhecimento do trabalho como um importante agente para a cura dos alienados, esses passam a ser descritos como um peso para os cofres públicos. Quando a promessa de cura alia-se à promessa de tornar o tratamento menos oneroso para o poder público, tornam-se mais marcantes as distinções entre contribuintes e indigentes no interior dos hospícios. Além disso, é produzida uma descontinuidade em relação ao valor das Colônias Agrícolas que, gradativamente, assumem a função de recolher os indivíduos tidos como indigentes e incuráveis. [...] Dentro e fora do hospício, sem descontinuidade, o trabalho se torna norma de conduta e passa a operar como um crivo que recai sobre a população, demarcando fronteiras e, especialmente, vidas que passam a ser manejadas como coisas públicas (NUNES; GUARESCHI, 2013, p. 95).

Essa forma de tratamento era da responsabilidade dos hospitais que arrogavam para si, mediante a autoridade médica sobre o paciente, o dever de endireitar os ditos desviados. "No tratamento moral, o hospital era o centro organizador da terapêutica, [...] em que os loucos, reduzidos a uma concepção infantilizada de sujeito, eram submetidos a castigos e correções morais" (GUERRA, 2004, p. 28).

Por esse viés, o trabalho nos manicômios estava longe de ser singularizante, criativo ou promotor de um processo de construção de sujeitos independentes. Além de forçar os internos a submeterem-se a atividades delineadas a priori, sem sua participação ativa, esse tipo de trabalho também reforçava o aprisionamento a atividades de menor importância e à lógica assistencialista, por se tratarem sempre de atividades assistidas, afogando, dessa forma, qualquer possibilidade de manifestação da subjetividade. Deste modo, '[...] existiu uma tradição na psiquiatria quanto ao uso de atividades artesanais nos hospitais psiquiátricos que se prestavam, dentre outras, à ocupação do tempo ocioso dos internos respaldado pela perspectiva terapêutica' (MORATO; LUSSI, 2015b, p. 340).

Tais atividades visavam muito mais a redução dos sintomas, sem se preocuparem tanto com a construção de novas possibilidades e espaços para os sujeitos em sofrimento psíquico e nem sempre eram vistas como transitórias.

Lappann-Botti e Labate (2004) sustentam que “[...] no início do século XX, o trabalho nas instituições psiquiátricas de Minas Gerais, apresentava-se como recurso econômico e organização da vida institucional, sendo também reconhecido como terapêutico para o alienado" (LAPPANN-BOTTI; LABATE, 2004, p. 520).

Tão logo os especialistas enunciam o trabalho como um recurso terapêutico, o trabalho dos internos é associado a uma espécie de indenização produzida para o Estado. Essa relação aparece tanto nas reflexões de Henrique Roxo sobre a Colônia Agrícola da Ilha do Governador, dirigida por Juliano Moreira, quanto na referência que o catedrático faz sobre a Colônia de Alienados de Juqueri, em São Paulo, cujo diretor era Franco da Rocha (NUNES; GUARESCHI, 2013, p. 94).

A utilização do trabalho e da atividade não nasceu dentro do território psiquiátrico, mas da pretensa necessidade de manutenção da ordem, no campo da assistência social e da polícia, lugares em que a loucura habitava, oferecendo-lhes uma solução nova, que, porém, fracassou devido à instabilidade econômica e ao desemprego gerado nas

Argum., Vitória, v. 12, n. 2, p. 202-219, maio/ago. 2020. | ISSN 2176-9575 
regiões circunvizinhas como resultado do trabalho gratuito e obrigatório realizado nas casas de internação (GUERRA, 2004). Referindo-se ao uso histórico do trabalho pela psiquiatria, a autora evoca a existência de três lógicas que antecedem a introdução das oficinas no campo da saúde mental.

A primeira é a lógica do desvio social: esta seria uma característica do século XVII, quando a loucura, tomada como mais uma das formas de desordem social, fez com que os loucos, junto com outros considerados desviados, passassem a ser recolhidos e confinados em asilos. Proliferaram pela Europa, esses lugares de aprisionamento de todos que eram tidos como desviados da razão, da moral, da economia e da sociedade. O hospital era uma estrutura jurídica julgadora e executora. A loucura e outras formas de improdutividade se tornaram caso de polícia. Não se queria curar, pretendia-se, isto sim, impedir a mendicância e o ócio trancafiando seus adeptos e praticantes em casas correcionais.

A segunda é a do desvio moral: esta emerge em meio ao fim do contexto ideológico de renovação e radicalização que demarcou o fim do século XVIII, na França e Europa. Neste contexto, a psiquiatria nasce como primeira especialidade médica, composta a partir da observação clínica dos fenômenos patológicos em internos. Conjuntura, esta que considera a loucura um desvio moral. Com isso o trabalho ganha uma importância ainda maior, sendo elevado a instrumento de restauração da ordem. É aqui também que emergem os experimentalismos de Pinel, que transforma a loucura em doença e alienação, ele sugere, ainda, utilizar o trabalho como recurso terapêutico na restituição da moral, sob os auspícios da autoridade médica, legitimando assim a psiquiatria e a emergência de uma nova relação com a loucura.

A terceira tem a ver com a tentativa de superação dos desvios da ortopedia psiquiátrica clássica ${ }^{2}$. Segundo ela, se o limiar do século XX marca o fim da clínica psiquiátrica, enquanto nosografia, também demarca o reavivar dessa mesma clínica enquanto terapêutica. É o momento de experiências inovadoras e inéditas e, por isso, diferentemente do século XVII (marcado pela internação), este seria o da invenção no campo da terapêutica na saúde mental. Com a decadência do modelo psiquiátrico tradicional, tratado também como produtor de marginalização e exclusão sociais, a assistência se reorganizou com base em modelos abertos e novos dispositivos de reabilitação, dentre os quais as oficinas, que aparecem como campo de resgate da singularidade da cidadania e da possibilidade de inserção social.

Em meio a essas lógicas históricas, surgem vários movimentos que tratam de fazer uma retomada do uso do trabalho sobre novas bases.

Nessa perspectiva, estes movimentos de resistência engendrados no final século XX têm forjado um repensar a respeito do lugar do louco na sociedade

${ }^{2}[$ [... $]$ nesse período a atividade e o trabalho se tornam, no campo terapêutico, propriedade e objeto da psiquiatria, sob a égide do pensamento e do tratamento moral. Aparecem em sua função terapêutica de restabelecimento da razão e de controle dos excessos, prescritos pelo médico psiquiatra. Reordenam moralmente, através do trabalho mecânico, as ações e atitudes dos internos, agora asilados em nome do tratamento médico edificado em torno da estrutura hospitalar (GUERRA, 2004, p. 28). 
e das formas de atenção e cuidado com este que desconstruam a lógica manicomial, produzindo subjetivações para além do modelo hospitalocêntrico da psiquiatria tradicional. As mudanças relacionadas à maneira de se referir ao louco aconteceram na medida em que se percebeu a importância da desconstrução do estigma que o designa como um sujeito incapaz tanto de governar sua vida como de trabalhar (ANDRADE; COSTA-ROSA, 2014, p. 31).

A Reforma Psiquiátrica Italiana, que emerge da experiência europeia, produziu uma virada na relação entre trabalho e loucura. A reforma europeia pode, segundo Guerra (2004), ser sintetizada em quatro pontos: (1) o médico ainda era o centro saber/poder quanto à prescrição da atividade terapêutica; (2) o da intenção adaptativa e de recuperação da mão-de-obra; (3) o momento em que se procura buscar atividades relacionadas à patologia e (4) quando se coloca em xeque a própria violência do modo de produção capitalista (MPC). Uma das ideias mais marcantes da reforma italiana tem a ver com a superação definitiva dos manicômios.

Inicialmente, os italianos se fundamentaram nas experiências de outros países como Inglaterra e França para colocar em discussão, junto com os pacientes, a instituição da psiquiatria e as demais instituições por ela produzidas. Posteriormente, romperam com estas, devido ao fato delas apenas modificarem as práticas psiquiátricas, não colocando em discussão a psiquiatria como tal e sua visão da loucura como doença (ANDRADE; COSTAROSA, 2014, p. 32).

O movimento da Psiquiatria Democrática também conhecida como Reforma Psiquiátrica Italiana se instaura, segundo Andrade e Costa-Rosa (2014), com a experiência de Basaglia no Hospital San Giovanni (Trieste). Sua fundação ocorre em 1973 quando foram postas em discussão, o desenrolar das atividades de técnicos e a ação da psiquiatria confrontando: o hospital psiquiátrico, o modelo da comunidade terapêutica inglesa e a política de Setor da França.

A Reforma Psiquiátrica no Brasil caracteriza-se pela sua relação com as possibilidades surgidas a partir da década de 1980 em que se iniciou o alargamento das liberdades políticas, permitindo que a mesma caminhasse no sentido da inclusão da loucura na cultura, muitas vezes por meio de centros de atenção psicossocial.

Um dos principais desafios da Reforma Psiquiátrica [...] é a potencialização do trabalho como instrumento de inclusão social dos usuários dos serviços. Embora os diversos serviços da rede de atenção à saúde mental fomentem a criação de cooperativas e associações e realizem oficinas de geração de renda, estas experiências, mesmo que com ótimos resultados, caracterizam-se, ainda, por sua frágil sustentação institucional e financeira. O manejo diário destas experiências com o mercado capitalista e com uma sociedade excludente impõe debates práticos e teóricos no cotidiano dos serviços, que vem substituindo aos poucos o componente da antiga reabilitação pelo trabalho, dado no marco asilar (BRASIL, 2005b, p. 36).

\section{As oficinas de trabalho e geração de renda}

Atualmente, por meio das iniciativas derivadas da reforma psiquiátrica, deflagrada nas décadas de 1980 e 1990, prevê-se a criação de serviços substitutivos ao modelo asilar e 
manicomial (Centros de Atenção Psicossocial (CAPS)) como eixos da rede de serviços de atenção em saúde mental, cujo objetivo é a reinserção social plena dos usuários por meio do lazer, trabalho, desenvolvimento da cidadania e fortalecimento dos laços familiares. Nesse sentido, o processo de reabilitação psicossocial traz à tona os desafios do envolvimento da família e da inclusão social, pelo trabalho dos usuários (FILIZOLA; TEIXEIRA; MILIONI; PAVARINI, 2011).

O Paradigma Psicossocial (PPS) está alicerçado nas propostas da Reforma Psiquiátrica que se consubstanciam no repúdio ao Paradigma Psiquiátrico Hospitalocêntrico (PPHM), tornando-se de todo modo uma tentativa de ultrapassagem do discurso manicomial, o que compreende um processo social complexo que obriga a transposição permanente dos mais diversos obstáculos sociais, econômicos, políticos e mesmo ideológicos. Tal exercício é facilitado pela confluência e reinvenção de práticas, conhecimentos, valores e modalidades de atenção.

A Reforma Psiquiátrica seria, portanto, um dos alicerces da proposta do Paradigma Psicossocial (PPS) “[...] expresso pelo conjunto de ações que se contrapõem ao Paradigma Psiquiátrico Hospitalocêntrico (PPHM)” (COSTA-ROSA, 2011, p. 51).

Ela representa, segundo Costa-Rosa (2011) “[...] um processo de superação expresso na passagem do discurso 'manicomial' ao da Reforma Psiquiátrica e do discurso desta à Atenção Psicossocial” (COSTA-ROSA, 2011, p. 49).

[...] a Reforma Psiquiátrica é um movimento social complexo, marcado por impasses, tensões, conflitos e desafios, tem como objetivo um conjunto de transformações de práticas, saberes, valores culturais e sociais, favorecendo a construção de novas modalidades de atenção em saúde mental (OLIVEIRA; PEDROZA; RODRIGUES; MACÊDO; PEREIRA, 2015, p. 97).

A psiquiatria tradicional foi fundamental para a construção e sustentação do PPHM, principalmente, por patologizar certas formas de existência, criar nosologias e classificações para aquilo que passou a considerar como doenças mentais decorrentes de causas biológicas - que deveriam ser isoladas em estabelecimentos, mediante, o confinamento dos seus portadores - e disseminar o uso do Manual Diagnóstico e Estatístico de Transtornos Mentais (DSM) como instrumento de diagnóstico e, consequentemente, de prescrição de medicamentos.

As contestações à psiquiatria tradicional que desaguaram em movimentos de sua reforma, nas décadas de 1980 e 1990, no Brasil, tornaram possível o surgimento de um outro paradigma que, segundo Costa-Rosa (2011), costuma ser designado de formas diversas em função dos momentos e contextos históricos: Práticas alternativas à Psiquiatria, Reforma Psiquiátrica, Atenção Psicossocial. Portanto, este novo paradigma (Paradigma Psicossocial (PPS)) relaciona-se estreitamente com as pulsações instituintes veiculadas pelos sujeitos e seu contexto histórico. Segundo o mesmo autor, "Sua lógica - expressa por concepções teóricas, técnicas, ideológicas e éticas -, seus ideais, e os interesses que visa, são contraditórios com os do PPHM" (COSTA-ROSA, 2011, p. 53). 
Ainda segundo o mesmo autor, esses dois paradigmas são contraditórios no que diz respeito à teoria, à técnica e à ética, determinando, em consequência, modos antagônicos de produção de subjetividade (Subjetividade Capitalística e Subjetividade Singularizada) ${ }^{3}$ e de produção de saúde.

É dentro dessa nova visão que podemos enquadrar, entre outras iniciativas, as oficinas de trabalho e geração de renda.

[...] a discussão acerca da importância do trabalho para os usuários da saúde mental passa a ter destaque, no Brasil, no âmbito do processo de Reforma Psiquiátrica, movimento que segundo Amarante teve início no final da década de 1970, no contexto de redemocratização do país (MORATO; LUSSI, 2015a, p. 67).

O trabalho tem seu lugar garantido neste processo, por ser um dos eixos da Reforma, “[...] junto à retaguarda assistencial através dos Centros de Atenção Psicossocial (CAPs), a retaguarda de moradia através do Sistema de Residências Terapêuticas e de reparação econômica através do programa De Volta para Casa (ANDRADE et al., 2013, p. 176)".

No Brasil, as iniciativas para tornar o trabalho um recurso terapêutico e de reinserção social plena dos usuários dos serviços de saúde mental, acompanham a história desses serviços e da própria psiquiatria.

Segundo Amarante (2008), as colônias de trabalho tiveram seu ideal de ocupação e tratamento pelo trabalho (praxiterapia) como marco da primeira reforma psiquiátrica brasileira. Em 1911 criaram-se as colônias masculina e feminina no Hospital Psiquiátrico Nacional do Rio de Janeiro, com as seguintes oficinas: ferraria, mecânica, elétrica, carpintaria e marcenaria, tipografia e encadernação, sapataria, colchoaria e vassouraria e pintura de paredes.

Foram abertas instituições parecidas, também, em Barbacena (MG), Barra do Piraí (RJ), Cuiabá (MS), São Luís (MA), Oliveira (MG), dentre outras cidades e regiões. É assim que, pela primeira vez no Brasil, dá-se a entrada do trabalho na psiquiatria como terapêutica para promover a recuperação dos ditos incuráveis ou crônicos. Deste modo, a exploração de sua mão de obra em prol da manutenção da colônia passou a fazer parte do pano de fundo da proposta de reinserção social plena do louco, Guerra (2004).

Na década de 1940, por influência de Nise Silveira (psiquiatra), o tratamento pelo trabalho muda de feições, dentre tantas, passando a ser escolha livre, tendo como finalidade primordial o tratamento dos pacientes e não o reforço das finanças da

3 "A subjetividade capitalística, tal como é engendrada por operadores de qualquer natureza ou tamanho, está manufaturada de modo a premunir a existência contra toda intrusão de acontecimentos suscetíveis de atrapalhar e perturbar a opinião. Para esse tipo de subjetividade, toda singularidade deveria ou ser evitada, ou passar pelo crivo de aparelhos e quadros de referência especializados. Assim, a subjetividade capitalístíca se esforça por gerar o mundo da infância, do amor, da arte, bem como tudo o que é da ordem da angústia, da loucura, da dor, da morte, do sentimento de estar perdido no cosmos" (GUATARRI, 2001, p. 33-34). 
instituição. Com esse novo espírito são desenvolvidas as mais variadas atividades, além dos tradicionais labores, inclusive, com preocupações estético-expressivas, recreativas e culturais, introduzindo-se, assim, pela primeira vez, uma grande diversificação de atividades terapêuticas, sem obrigatoriedade (GUERRA, 2004).

No bojo das iniciativas que procuravam possibilitar aos internos dos hospitais psiquiátricos uma vida ativa com vistas a sua emancipação e reintegração social frutificaram e ganharam espaço, na reforma psiquiátrica brasileira das décadas de 1980 e 1990, cujos efeitos se prolongam aos dias atuais, as iniciativas ligadas ao trabalho cooperativo e outros empreendimentos de geração de renda vinculados às políticas e programas governamentais assentados nos princípios da economia solidária (VOLZ et al., 2015; BURKE; BIANCHESSI, 2013; MORATO; LUSSI, 2015a).

Destaca-se a criação do Grupo de Trabalho Interministerial (BRASIL, 2005a) como um dos avanços importantes para garantir a solidificação das propostas de emancipação dos usuários, por meio da inclusão pelo trabalho.

A economia solidária ${ }^{4}$ faz parte das mais novas estratégias do Governo Federal na reabilitação de pessoas em sofrimento psíquico: uma ação que se faz materializar por meio de redes de cooperação entre a Secretaria Nacional de Economia Solidária, (criada em 2003) com outros órgãos. Um bom exemplo dessa iniciativa governamental é a Portaria Interministerial no 353/2005 de 7 de Março de 2005, subscrita pelo Ministério da Saúde e pelo Ministério do Trabalho e Emprego, (BRASIL, 2005a). Como resultado imediato desta portaria, criou-se o Grupo de Trabalho de Saúde Mental e Economia Solidária (Art.1 ${ }^{\circ}$ ) e o Fórum Brasileiro de Economia Solidária (FBES), como um de seus órgãos mais atuantes. Este último é regido por uma carta de princípios aprovada como guia do Fórum Brasileiro de Economia Solidária, composto de três partes: História e cenário atual, Princípios gerais e específicos e Definição da economia solidária (FÓRUM BRASILEIRO DE ECONOMIA SOLIDÁRIA, 2014).

Com as primeiras Oficinas de Experiências de Geração de Renda e Trabalho de Usuários de Serviços de Saúde Mental (em 2004), mediante uma articulação entre os Ministérios da Saúde e do Trabalho e Emprego, foram criadas as bases de diálogo entre as políticas de saúde mental e economia solidária (MORATO; LUSSI, 2015b).

As experiências de trabalho cooperativo ou os empreendimentos cooperativos podem ser definidos como uma variedade de relações de mercado ou de subsistência em que exista partilha dos meios de produção e consumo, do trabalho, dos rendimentos do trabalho, conhecimento (tecnológico-produtivo-gestionário) e do poder de decisão sobre o negócio pelos partícipes do empreendimento sob os princípios da igualdade e da solidariedade (CRUZ, 2004).

\footnotetext{
4 [...] essas organizações assumem, ao mesmo tempo, funções de espaços produtivos, geradores de bens, serviços e empregos; de espaços de proximidade, geradores de socialização; e de espaços públicos, geradores de reflexão e de ações políticas. Estas características constituem o pano de fundo para compreensão dos princípios e práticas de gestão aplicáveis a este tipo de organização (ANDION, 2005, p. 85).
} 
As cooperativas de trabalho também são "[...] formas autogestionárias de organização da produção, do controle da atividade laboral e do produto realizado pelos próprios trabalhadores" (LIMA, 2009, p. 91). Segundo Pedroza, Oliveira, Fortunato e Soares (2012), o manicômio de San Giovanni foi, provavelmente, o pioneiro na adoção da experiência de cooperativa para a inclusão de pessoas em sofrimento psíquico, em 1970.

As oficinas de geração de renda, baseadas em empreendimentos cooperativos e de economia solidária, estão em consonância com as propostas da Reforma Psiquiátrica, pois são norteadas por uma ética humanizadora, democrática e que, por conseguinte, poderia ser considerada mais justa em comparação com aqueles que, ainda, funcionam em estreita relação com o modo de produção capitalista (MPC). Porém, como aponta Cruz (2004), estas iniciativas se encontram circundadas por um mercado dominado pelas relações sociais que elas rechaçam (capitalistas), não desconsiderando, é claro, que em boa parte das vezes este rechaço resulte de experiências práticas (empíricas).

O percurso da linha tênue, de um lado agente de manutenção do capitalismo, de outro agente mobilizador social para a edificação da Economia Solidária, exige elucidação sobre a navalha desse caminhar e, acima de tudo, ações concretas para compor enfrentamentos políticos necessários para a consolidação da solidariedade que se pretende (FERRO; MACEDO; LOUREIRO, 2015, p. 114).

Estas experiências são vistas de modo geral de duas formas: iniciativas de geração de trabalho e renda (Rede Brasileira) e iniciativas de inclusão social pelo trabalho (CIST), além dos próprios empreendimentos de saúde mental e economia solidária e de cooperativas sociais, refletindo sua singularidade e as diferentes concepções sobre a relação entre loucura e trabalho (ANDRADE et al., 2013).

\section{O trabalho na (a-)ética capitalista}

A reinserção social plena dos usuários da saúde mental se torna problemática quando consideramos que o modo de produção capitalista (MPC) é o dominante no mundo contemporâneo do trabalho e na nossa sociedade.

Para Burke e Bianchessi (2013) "Na nossa sociedade capitalista, onde a hipervalorização da produção e do lucro constituem as organizações, percebemos o quão é difícil buscar a (re)inserção do usuário" (BURKE; BIANCHESSI, 2013, p. 967).

As relações de trabalho que se encontram enquadradas no MPC, o qual funciona apenas de acordo aos interesses do capital, criam sofrimento para os trabalhadores, sejam eles usuários ou não dos serviços de saúde mental.

Inserir não significa incluir, uma vez que se absorvidos por organizações de trabalho, sem meios e condições adequados para a realização do mesmo e sem perspectivas de desenvolvimento profissional e de justiça social, o trabalho pode tornar-se mais uma fonte de riscos à saúde e forma nítida de reprodução das práticas de exclusão, posto que a desigualdade de oportunidades, reproduzida nos contextos de trabalho também dificulta a inclusão, ou seja, a 
possibilidade de relacionar-se, de desenvolver-se e de realizar o trabalho em condições adequadas às suas necessidades (LEVATTI; FEIJÓ; GOULART JÚNIOR; CAMARGO, 2015, p. 72-73).

As transformações das relações de trabalho, ao longo do desenvolvimento do capitalismo e do liberalismo, criaram subordinações cada vez maiores do trabalho ao capital com o aumento da concentração de renda, desvalorização da força de trabalho, aumento do desemprego estrutural, enfraquecimento das organizações dos trabalhadores e flexibilização das leis de proteção e garantia de direitos aos trabalhadores.

A revolução industrial promoveu a expansão do capitalismo, acelerou e tornou mais profunda e perniciosa a subsunção do trabalho (perda de autonomia do trabalhador), esvaziou o trabalho e o precarizou, enquanto as regras do trabalho, rotinas, estrutura e ritmos, passaram a ser, de certa forma, definidos pelas máquinas. Antunes (2011) também se refere a essa mudança discutindo o quanto a substituição do homem pela máquina se tornou um elemento chave para lógica do capital;

O crescente processo de eliminação de trabalho vivo pelo trabalho morto, de substituição de trabalhadores por tecnologia maquínica, foi outro traço central na sujeição que a máquina-ferramenta - em verdade, a lógica movida pelo sistema do capital - impôs ao trabalho, reduzindo e mesmo eliminando sua destreza oriunda da fase artesanal e mesmo manufatureira, consolidando o processo de desumanização do trabalho, ou, mais rigorosamente, a 'desantropomorfização do trabalho', para usar uma formulação do Lukács [...] (ANTUNES, 2011, p. 124).

Deste modo, se por um lado a revolução industrial trouxe ganhos no que diz respeito ao aumento da produtividade e à substituição do trabalho manual, não é possível ignorar os efeitos perniciosos do capital que, usando agora as máquinas, criou novas formas de esvaziamento do trabalho. Deste modo, o capitalismo, com a apropriação do saber técnico-científico, materializado pela introdução da máquina no espaço da fábrica, trouxe uma configuração contraditória para o trabalho. Como nos dizem Navarro e Padilha (2007), "[...] ao mesmo tempo em que o trabalho é a fonte de humanização e é o fundador do ser social, sob a lógica do capital se torna degradado, alienado, estranhado" (NAVARRO; PADILHA, 2007, p. 15).

Diante dessa situação, nas palavras de Marx (1964), se vê ilustrada a desolação provocada por este trabalho, que está inserido na lógica capitalista, deste modo:

O trabalhador se torna tão mais pobre quanto mais riqueza produz, quanto mais a sua produção aumenta em poder e extensão. O trabalhador se torna uma mercadoria tão mais barata, quanto mais mercadoria cria. Com a valorização do mundo das coisas aumenta em proporção direta a desvalorização do mundo dos homens. O trabalho não produz só mercadorias; produz a si mesmo e ao trabalhador como uma mercadoria, e isto na proporção em que produz mercadorias em geral (MARX, 1964, p. 80).

Com a constatação de que o MPC é o dominante e se infiltra em todas as esferas da vida, Quinet (2006) afirma "O capital invadiu tudo [...]" (QUINET, 2006, p. 39). Por 
conseguinte as relações sociais se tornam relações com os objetos e não mais com as pessoas, "[...] o vinculo social entre as pessoas se transforma em uma relação social entre coisas: a capacidade pessoal transfigura-se em capacidade das coisas. Trata-se, portanto, de uma relação reificada e coisificada entre os seres sociais" (ANTUNES, 2011, p. 124).

Uma relação na qual a mercadoria se torna a mediadora entre os homens, pois já não se trata mais de uma relação entre pessoas, mas entre mercadorias, entre coisas.

Aqui, os produtos do cérebro humano parecem dotados de vida própria, como figuras independentes que travam relação umas com as outras e com os homens. Assim se apresentam, no mundo das mercadorias, os produtos da mão humana. A isso eu chamo de fetichismo, que se cola aos produtos do trabalho tão logo eles são produzidos como mercadorias e que, por isso, é inseparável da produção de mercadorias (MARX, 2013, p. 148).

Quinet (2006) considera que o discurso que emerge no MPC, “[...] na verdade é um discurso que exclui o outro do laço social, pois o sujeito só se relaciona com os objetosmercadoria comandado pelo significante-mestre, o capital. É um discurso que não faz laço social [...]" (QUINET, 2006, p. 39). Deixando ainda mais evidente a perniciosidade do capitalismo e transformando "[...] cada um num explorador em potencial de seu semelhante para dele obter um lucro de um sobretrabalho não contabilizado [...]" (QUINET, 2006, p. 39). Ainda segundo Quinet (2006), o capitalista e o proletário não possuem vínculo, mesmo porque a figura do primeiro tende a desaparecer, substituindo-se pela figura impessoal do capital globalizado. Como dominante, o discurso capitalista sobrepõe o mercado à sociedade.

Ao tratarmos desta problemática, ocasionada pelo MPC, devemos acrescentar as questões inerentes à própria precarização do trabalho que surgiram, recentemente, com as mudanças ocasionadas pelas revoluções tecnológicas e a introdução das Tecnologias de Informação e de Comunicação (TIC's), permitindo rearranjos antes impensáveis sobre jornadas de trabalho, subcontratos, regulação de horários e tantos outros.

Castel (1998), percorrendo as metamorfoses das questões sociais do século XIV, caracterizado por ele como o século da constituição das sociedades tutelares, passando pela sociedade salarial que emerge no século XIX, sob o liberalismo, e chegando aos nossos dias, destaca a vulnerabilidade produzida pela precarização do trabalho, pela fragilização dos vínculos trabalhistas e, consequentemente, pelo processo de desfiliação. Com efeito, proteções mínimas do Estado sob a forma de garantias trabalhistas ou até mesmo da concessão de benefícios sociais foram progressivamente retiradas, enfraquecendo o papel do salário como produtor de vínculo social e de segurança, com isso, gerando uma condição de temor e insegurança. O emprego e o salário que antes asseguravam uma vinculação social básica e certa estabilidade, assim sendo se tornaram voláteis, no conjunto do que se passou a chamar de flexibilização das relações de trabalho, abrandando os vínculos e aprofundando a vulnerabilidade e a instabilidade do mundo do trabalho, também presentes em outras relações e vínculos psicossociais. 
Dessa forma, o trabalho é entendido, não somente como uma relação econômica, mas como uma forma de inserção social, como um processo de vinculação e de filiação que pode gerar situações de estreitamento, estabilidade de contatos e provimento de garantias ou situações opostas de fragilização ou até mesmo de desvinculação ou desfiliação. Importante acrescentar que o trabalho não tem como função tão somente a geração de renda, mas também é produtor de relações e vinculações socioafetivas. Por meio dele se produz sentimentos de aceitação/rejeição, confiança/desconfiança, segurança/perigo, competência/incompetência, sucesso/fracasso e tantos outros. Assim sendo o desempregado, o redundante descartado do mercado de trabalho ou aqueles que persistem em trabalhos informais, precarizados ou uberizados (Fontes, 2017), tornam-se desprovidos de garantias e direitos, com baixa remuneração e exigência de jornadas, praticamente, sem limite de tempo.

Portanto, a a-ética do trabalho no capitalismo é o grande entrave para se pensar o trabalho como meio de reinserção social plena, se levarmos em consideração as implicações de um trabalho alienante na reintegração dos sujeitos em sofrimento psíquico, numa sociedade em que já se sabe a princípio, ser este um espaço extremamente adoecedor para o trabalhador. Ao enquadramos o mundo do trabalho como um dos vários lugares sequestrados pelo MPC será fácil entender como a ideia de reinserção social plena pelo trabalho precisa ser com frequência problematizada, a menos que se queira prosseguir com alguma forma de disciplinarização e controle eventualmente presentes até mesmo em práticas da atenção psicossociais que pretendam ser revolucionárias 5 .

Se partirmos do princípio de que o sofrimento daquele usuário se produziu, ou está sendo produzido (continuamente), em meio a uma sociedade que funciona nessa lógica perversa, seria, por conseguinte, igualmente perverso restituí-lo ao seu algoz e aqui para reforçar nossa posição convém dizer que, "[...] a inserção em contextos desiguais e inadequados de trabalho pode aumentar a vulnerabilidade [...]" (LEVATTI; FEIJÓ; GOULART JÚNIOR; CAMARGO, 2015, p. 7o)”.

\section{Considerações finais}

O uso do trabalho no campo da saúde mental está longe de ser uma ideia realmente nova, porém, hoje é implementado sobre novas bases. A forma como compreendemos a relação entre trabalho e loucura se modificam ao longo da História, tomando as mais diferentes feições, em que podemos dizer que a valorização do trabalho que longe de ser apenas uma tentativa de submeter todos à obrigatoriedade da produção, encerra a ideia da utilização do mesmo como instrumento moral.

As oficinas de trabalho e geração de renda são atualmente, o grande veículo de uso da atividade e do trabalho para a reabilitação psicossocial e reinserção social plena, dentro de serviços de saúde inspirados no movimento da Reforma Psiquiátrica, serviços que procuram promover o resgate da singularidade, da cidadania e da sociabilidade plena. É necessário, contudo, levar em consideração entraves, contradições e possíveis desvios que podem surgir no que diz respeito à questão da reinserção social plena pelo

5 Ver Tenório (2007). 
trabalho, levando em conta que não haveria um efeito sustentável na produção de saúde por meio do trabalho se o mesmo reproduzisse as relações do modo de produção capitalista ou se a opção pelo modelo cooperativo, dentro da economia solidária, for apenas um recurso temporário e superficial, onde: (1) não haja espaço para discussão do enquadramento da economia solidária e do cooperativismo como um modo alternativo de produção da sociedade e não um simples artifício ocasional; (2) desconsidere-se que o sujeito, findo o tratamento, será possivelmente devolvido a uma forma de trabalho que não se baseia em valores de cooperação, resultando numa prática que apenas sirva para alimentar, ao contrário do que se desejava (promoção de saúde), um processo cíclico de produção de sofrimento, no qual as oficinas, sirvam somente, tal como os medicamentos, para tamponar os sintomas e mandar de volta os sujeitos para o mesmo lugar que os colocara em sofrimento.

Nessa linha de raciocínio, apenas seria plausível a via do trabalho como forma de minimização do sofrimento psíquico se houvesse condições de se mudar, não somente o direcionamento dado ao trabalho nas instituições de saúde mental (mesmo à luz dos novos paradigmas propostos), mas também na própria sociedade como um todo. Isto é, não basta modificar a organização e o sentido do trabalho no interior das instituições de saúde ou nos seus serviços estendidos, mas é também necessário construir uma sociedade mais equitativa, democrática promotora de relações que privilegiem o laço social entre as pessoas e não com as coisas e que não tenha o capital como mediador das interações sociais. Em suma trata-se de promover uma sociedade que tenha por princípio reorganizar-se com base num modo de produção singularizante, humanizante e principalmente, que não tenha o capital como pedra de toque; uma sociedade que, como pensou Marx, extinga as relações perniciosas, que por ora se mantêm com o capital. Aliás, como professam alguns defensores do modelo da atenção psicossocial (AMARANTE, 2008; COSTA-ROSA, 2011), um dos pontos chave deste modelo, essencial para seu êxito, é a mudança da cultura em relação à loucura. É necessário acrescentar ao posicionamento desses autores o seguinte: tal mudança de cultura não diz respeito apenas a mudanças abstratas acerca da simbolização da loucura, revendo concepções e valores, mas, também e, sobretudo, a mudanças nas relações sociais de base, fundadas no trabalho, capazes de restituir a singularidade no trabalho e livrá-lo da profunda alienação. Mudanças essas que, tais como quaisquer outras mudanças de base, atingiriam a todos e não somente aqueles tipificados como pessoas em sofrimento psíquico e capturados pelos serviços de saúde mental.

Quiçá essa poderia ser a contribuição dos loucos e da loucura ao mundo atual: denunciar com sua condição extrema de alienação, a alienação que grassa os sujeitos da atualidade e evidenciar a desolação causada pelo modo de constituição a que estavam submetidos e a impossibilidade de voltar ao mesmo enquanto a situação se mantiver inalterada.

\section{Referências}

AMARANTE, P. Saúde mental e atenção Psicossocial. 2. ed. Rio de Janeiro: Editora Fiocruz, 2008. 
ANDION, C. A gestão no campo da economia solidária: particularidades e desafios. RAC, v. 9, n. 1, p. 79-101, 2005.

ANDRADE, M. C.; COSTA-ROSA, A. O encontro da loucura com o trabalho: concepções e práticas no transcurso da história. Gerais: Revista Interinstitucional de Psicologia, São João Del-Rei, v. 7, n. 1, p. 27-41, 2014.

ANDRADE, M. C.; BURALI, M. A. de; VIDA, A.; FRANSOZIO, M. B. B.; SANTOS, R. Z. Dos. Loucura e trabalho no encontro entre saúde mental e economia solidária.

Psicologia: ciência e profissão, Brasília (DF), v. 33, n. 1, p. 174-191, 2013.

ANTUNES R. Os exercícios da subjetividade: as reificações inocentes e as reificações estranhadas. Caderno CRH, Salvador, v. 24, n. esp. 1, p. 121-131, 2011.

BRASIL. Grupo de Trabalho Interministerial. Portaria Interministerial no 353 , de 07 de Março de 2005. Institui o Grupo de Trabalho de Saúde Mental e Economia Solidária e dá outras providências. Brasília (DF), 2005a. Disponível em: http://www.fenix.org.br/portariainterministerial353-marco-2005.pdf. Acesso em: 27 abr. 2014.

BRASIL. Ministério da Saúde. Reforma psiquiátrica e política de saúde mental no Brasil. In: CONFERÊNCIA REGIONAL DE REFORMA DOS SERVIÇOS DE SAÚDE MENTAL: 15 ANOS DEPOIS DE CARACAS. Brasília (DF): OPAS, $2005 \mathrm{~b}$.

BÜRKE, K. P.; BIANCHESSI, D. L. C. O trabalho como possibilidade de (re)inserção social do usuário de um Centro de Atenção Psicossocial na perspectiva da equipe e do usuário. Estudos e Pesquisas em Psicologia, Rio de Janeiro, v. 13, n. 3, p. 957-976, 2013. Disponível em:

http://pepsic.bvsalud.org/scielo.php?script=sci_arttext\&pid=S18o842812013000300009\&lng=pt\&tlng=pt. Acesso em: 12 set. 2016.

CASTEL, R. As metamorfoses da questão social: uma crônica do salário. Rio de Janeiro: Vozes, 1998.

\section{COSTA-ROSA, A. Operadores fundamentais da Atenção Psicossocial:}

contribuição a uma clínica critica dos processos de subjetivação na saúde coletiva. 2011. Tese (Livre-docência)-Faculdade de Ciências e Letras de Assis, Universidade Estadual Paulista, Assis, São Paulo, 2011.

CRUZ, A. Economia solidária: a construção de um conceito e a consolidação de um novo objeto de investigação na ciência econômica. Cadernos de Economia Chapecó: UNOESC, v. 8, p. 93-120, 2004.

FERRO, L. F.; MACEDO, M. de; LOUREIRO, M. B. Economia solidária, saúde mental e a prática do terapeuta ocupacional: relatos de participantes de um grupo de geração de trabalho e renda. Cad. Ter. Ocup, v. 23, n. 1, p. 101-116, 2015. 
FILIZOLA, C. L. A., TEIXEIRA, I. M. DE C., MILIONI, D. B.E PAVARINI S. C. I. Saúde mental e economia solidária: a família na inclusão pelo trabalho. Rev Esc Enferm USP, São Paulo, v. 45, n. 2, p. 418-425, 2011.

FOUCAULT, M. História da loucura na idade clássica. São Paulo: Editora Perspectiva, 1978.

FÓRUM BRASILEIRO DE ECONOMIA SOLIDÁRIA (FBES). A trajetória do Movimento da Economia Solidária no Brasil: do Fórum Social Mundial (FSM) ao Fórum Brasileiro da Economia Solidária, 2014. Disponível em: http://www.itcp.coppe.ufrj.br/rede_gestores/pdfs/5_principios.pdf. Acesso em: 22 abr. 2016.

FONTES, V. Capitalismo em tempos de uberização: do emprego ao trabalho. Revista Marx e o Marxismo, v. 5, n. 8, p. 45-67, 2017.

GUATTARI, F. As três ecologias. São Paulo: Papirus, 2001.

GUERRA, A. M. C. Oficinas em saúde mental: percurso de uma história, fundamentos de uma prática. In: COSTA C. M.; FIGUEIREDO, A.C. Oficinas terapêuticas em saúde mental: sujeito, produção e cidadania. Rio de Janeiro: Contra Capa, 2004.

LAPPANN-BOTTI, N. C.; LABATE, R. C. Oficinas em saúde mental: a representação dos usuários dos serviços de saúde mental. Texto \& Contexto - Enfermagem, Florianópolis, v. 13, n. 4, p. 519-526, 2004. https://dx.doi.org/10.159o/So10407072004000400003 .

LEVATTI, G. E., FEIJÓ, M. R., GOULART JÚNIOR, Edward; CAMARGO, M. L. Considerações sobre a Inclusão de Pessoas com Diagnóstico de Transtorno Mental no Trabalho. Revista Laborativa, Assis, v. 4, n. 2, p. 64-84, 2015. Disponível em: http://ojs.unesp.br/index.php/rlaborativa/article/view/1274/pdf. Acesso em: 21 jul. 2016.

LIMA, J. C. Cooperativas de trabalho. In: CATTANI, A. D.; LAVILLE, J. L.; GAICER, L. I.; HESPANHA, P. (Coord.). Dicionário Internacional da Outra Economia. São Paulo: Almedina Brasil, 2009.

MARX, K. O capital: crítica da economia política: Livro I: O processo de produção do capital. (ENDERLE, R. Trad.). São Paulo: Boitempo editorial, 2013.

MARX, K. Manuscritos Econômico-Filosóficos. Lisboa: Edições 70, 1964.

MORATO, G. G.; LUSSI, I. A. O. A prática do terapeuta ocupacional em iniciativas de geração de trabalho e renda: contribuição dos fundamentos da profissão e das dimensões da categoria trabalho. Rev Ter Ocup Univ São Paulo, São Paulo, v. 26, n. 1, p. 66-73, $2015 \mathrm{a}$. 
MORATO, G. G.; LUSSI, I. A. O. Caracterização de iniciativas de geração de trabalho e renda destinadas a usuários de serviços de saúde mental e aproximação com a economia solidária: a realidade do Estado de São Paulo. Rev Ter Ocup Univ São Paulo, São Paulo, v. 26, n. 3, p. 336-344, 2015b.

NAVARRO, V.L.; PADILHA, V. Dilemas do Trabalho no Capitalismo Contemporâneo. Psicologia \& Sociedade, Recife, v. 19, n. 1, Edição Especial, p. 14-20, 2007.

NUNES, K. G.; GUARESCHI, N. M. de F. Práticas de cuidados da alienação mental: o trabalho como prescrição terapêutica. Mnemosine, Rio de Janeiro, v. 9, n. 1, p. 81-105, 2013.

OLIVEIRA, F. B. de; PEDROZA, A. P.; RODRIGUES, E. T.; MACÊDO, M. A.; PEREIRA, T. K. A. Reforma psiquiátrica, economia solidária e inclusão social. Ciência e Sustentabilidade - CeS, Juazeiro do Norte, v. 1, n. 1, p. 96-107, 2015.

PEDROZA, A. P.; OLIVEIRA, F. B.; FORTUNATO, M. L.; SOARES, P. F. C. Articulação saúde mental e economia solidária: relato de projeto de inclusão social. Rev Rene, Fortaleza, v. 13, n. 2, p. 454-462, 2012.

QUINET, A. Psicose e laço social: esquizofrenia, paranóia e melancolia. Rio de Janeiro, SJ: Jorge Zahar, 2006.

TENÓRIO, F. Questões para uma atualização da agenda da Reforma Psiquiátrica. In: COUTO, M. C. V.; MARTINEZ, R. G. (Orgs.). Saúde Mental e Saúde Pública: questões para a agenda da Reforma Psiquiátrica. Rio de Janeiro: NUPPSAM/IPUB/UFRJ, 2007.

VALLADARES, A. C. A.; LAPPANN-BOTTI, N. C.; MELLO, R.; KANTORSKI, L. P.; SCATENA, M. C. M. Reabilitação psicossocial através das oficinas terapêuticas e/ou cooperativas sociais. Revista Eletrônica de Enfermagem, Goiânia, v. 5, n. 1, p. 4-9, 2003. Disponível em: https://www.revistas.ufg.br/fen/article/view/768/851. Acesso em: 12 maio 2016.

VOLZ, P. M. et al. A inclusão social pelo trabalho no processo de minimização do estigma social pela doença. Saúde Soc. São Paulo, São Paulo, v. 24, n. 3, p. 877-886, 2015 .

Felizardo Tchiengo Bartolomeu COSTA Trabalhou na redação do artigo e na sua revisão crítica. Doutor em Psicologia pela Faculdade de Ciências e Letras de Assis (UNESP). Actualmente é docente e Director Geral Adjunto para Área Científica da Escola Superior Pedagógica do Bengo, Angola. Actua em, psicologia social, psicologia organizacional e do trabalho, imigração e transnacionalismo e em educação (formação de professores). Membro do Grupo de Pesquisa Figuras e modos de subjetivação no contemporâneo, do(a) Universidade Estadual Paulista Júlio de Mesquita Filho, na qualidade de colaborador estrangeiro. 
José Sterza JUSTO Trabalhou na redação do artigo e na sua revisão crítica.

Graduação em Psicologia pela Universidade Estadual Paulista Júlio de Mesquita Filho (1975). Mestre em Psicologia Educacional pela Pontifícia Universidade Católica de São Paulo (1981). Doutorado em Psicologia (Psicologia Social) pela Pontifícia Universidade Católica de São Paulo (1989) e Livre-Docência em Psicologia do Desenvolvimento pela UNESP-Campus de Assis. Atualmente é professor Livre-Docente do Programa de Pós-Graduação em Psicologia da Faculdade de Ciências e Letras da Universidade Estadual Paulista (UNESP-Campus de Assis). Ministra disciplinas na pós-graduação, orienta mestrados e doutorados e desenvolve pesquisas na área de Psicologia Social com ênfase na produção de subjetividade (transubjetividade) em condições de trajetividade, mobilidade psicossocial, itinerância,nomadismo e errância. Tem como foco principal de pesquisa andarilhos de estrada, "trecheiros", pessoas em situação de rua e migrantes. 